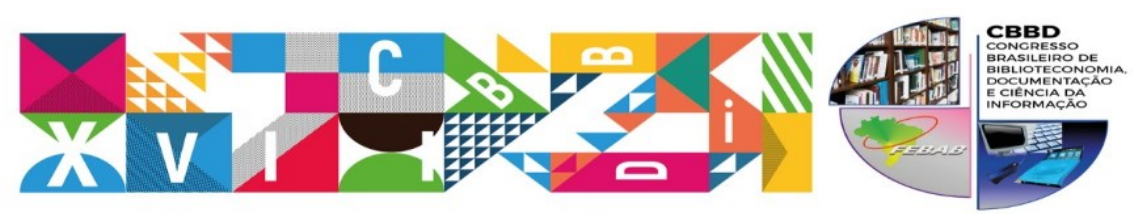

XXVII CONGRESSO BRASILEIRO DE BIBLIOTECONOMIA,

DOCUMENTAÇÃ̃O E CIÊNCIA DA INFORMAÇĀO

TEMA CENIRAL: Objetivos para o Desenvolvimento Sustentável das Naçōes Unidas:
como as bibliotecas podem contribuir com a implementação da Agenda 2030

Eixo 8 - Advocacy, Inovação e Empreendedorismo

\title{
ECOSSISTEMA DE STARTUPS EM FLORIANÓPOLIS: possibilidades para profissionais da Biblioteconomia
}

\author{
Priscila Machado Borges Sena \\ Doutoranda em Ciência da Informação \\ pela Universidade Federal de Santa \\ Catarina. \\ E-mail: priscilasena.ufsc@gmail.com
}

\section{UrsulaBlattmann}

Pós-doutorado pela Universidade Federal de Pernambuco no Programa de Pós-graduação em Ciência da Informação. Professora da Universidade Federal de Santa Catarina nas áreas de Biblioteconomia, Arquivologia e Ciência da Informação.

E-mail: ursula.blattmann@ufsc.br

\section{Clarissa Stefani Teixeira}

Pós-doutorado pela Universidade Federal de Santa Catarina. Professora adjunta do Departamento de Engenharia do Conhecimento da Universidade Federal de Santa Catarina. E-mail: clastefani@gmail.com

\section{RESUMO}

Florianópolis é uma capital que tem se destacado em aspectos relacionados à inovação e empreendedorismo no Brasil, por exemplo,o investimento no Sapiens Parque. Contexto que suscita questionamentos quanto às possibilidades de atuação para profissionais da Biblioteconomia, bem como sobre as habilidades, competências e atitudes pertinentes para o Ecossistema de Startups em Florianópolis. 0 objetivo do estudo visa indicar possibilidades de atuação profissional da área de Biblioteconomia no Ecossistema de Startups de Florianópolis, e delinear as competências, habilidades e atitudes fundamentais para esse ambiente, à luz das Competências para Profissionais da Informação da Special Libraries Association (SLA). Foi realizada uma pesquisa exploratória-descritiva para caracterização de um Ecossistema de Startups, relacionando-o com as Competências para Profissionais da Informação da SLA, por meio de uma abordagem qualitativa. A análise realizada torna perceptível e necessária a participação do profissional da Biblioteconomia no contexto do Ecossistema de Startups de Florianópolis. Ao comparar as competências para Profissionais da Informação da Special Library Association com as características de um Ecossistema de Startups, verificou-se que estas são pertinentes, em virtude dessas comunidades se constituírem baseadas na multiplicidade de conhecimentos de distintos atores no fluxo da informação. Recomenda-se aprofundar estudos acerca das diferentes competências, habilidades e atitudes necessárias, com vistas a fortalecer a base teórica e práticas da área.

Palavras-chave: Ecossistema de Startups. Biblioteconomia. Special Libraries Association. Startups. Biblioteconomia e Startups. 


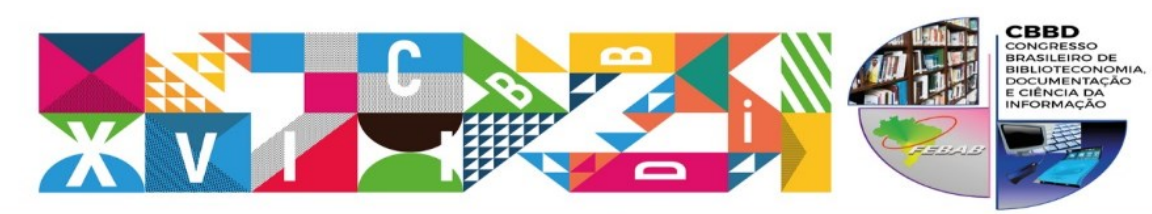

XXVII CONGRESSO BRASILEIRO DE BIBLIOTECONOMIA, DOCUMENTAÇĀO E CIÊNCIA DA INFORMAÇĀO

TEMA CENIRAL: Objetivos para o Desenvolvimento Sustentável das Naçōes Unidas:
como as bibliotecas podem contribuir com a implementação da Agenda 2030

STARTUPS ECOSYSTEM IN FLORIANÓPOLIS: possibilities for professionals from Librarianship

\begin{abstract}
Florianópolis is a capital that has been outstanding in aspects related to innovation and entrepreneurship in Brazil, one of the examples of this is the investment in science and technology Sapiens Park. This context raises questions about the possibilities of acting for library professionals, skills, competences and attitudes pertinent to the Startups Ecosystem in Florianópolis. The objective of this study was to indicate the possibilities of action for Library Science professionals in the Startups Ecosystem of Florianópolis, and the skills, abilities and attitudes fundamental to this environment, in the light of the Special Libraries Association's Information Skills. It can be classified as exploratory-descriptive, as it performed the characterization of a Startups Ecosystem, relating it to the SLA Information Professional Competencies, through a qualitative approach. The analysis made perceptible and necessary the participation of the Librarianship Professional in the context of the Startups Ecosystem of Florianópolis. By crossing the skills of Information Professionals from the Special Library Association with the characteristics of a Startups Ecosystem, they were found to be relevant because these communities are based on the multiplicity of knowledge of different actors in the information flow. It is recommended to deepen studies on the different competences, abilities and attitudes needed, with a view to strengthening the theoretical and practical basis of the area.
\end{abstract}

Keywords: Startups Ecosystem. Librarianship. Special Libraries Association. Startups. Librarianshipand Startups.

\title{
1 INTRODUÇÃO
}

As crises econômicas dos últimos anos têm instigado o desenvolvimento de formas diferenciadas de empreendedorismo. As startups, empresas com ideias inovadoras 


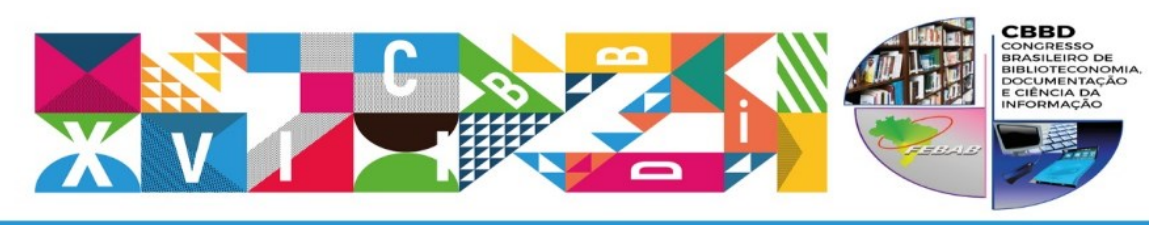

\section{CONGRESSO BRASILEIRO DE BIBLIOTECONOMIA, DOCUMENTAÇĀO E CIÊNCIA DA INFORMAÇĀO \\ TEMA CENIRAL: Objetivos para o Desenvolvimento Sustentável das Naçōes Unidas:
como as bibliotecas podem contribuir com a implementação da Agenda 2030}

alicerçadas em tecnologias deinformação e comunicação nascem pequenas, geram novas oportunidades de trabalho e são projetadas para crescerem rapidamente. Ganham incentivo e visibilidade devido estimular a cultura empreendedora em todo o planeta.

Florianópolis, cidade no estado de Santa Catarina é uma capital que tem se destacado nesse aspecto no Brasil, um dos exemplos disso é o investimento no Sapiens Parque (SAPIENS PARQUE, 2016), e as indicações da Endeavor como sendo esta a segunda melhor cidade brasileira para se empreender (ENDEAVOR, 2016). Nesse contexto, torna-se pertinente indagar sobre as possibilidades de atuação para profissionais da Biblioteconomia, bem como sobre as competências, habilidades e atitudes pertinentes para o Ecossistema de Startups em Florianópolis, à luz das Competências para Profissionais da Informação da Special Libraries Association (SLA).

Quanto a SLA, trata-se de uma organização global sem fins lucrativos para profissionais de informação inovadores e seus parceiros estratégicos em negócios, governos, instituições acadêmicas e outras configurações "especializadas" (SLA, 2016). Diante disso, entende-se que as competências listadas pela a associação para profissionais da informação, podem agregar aos profissionais da Biblioteconomia atuantes, ou aqueles que pretendem atuar no Ecossistema de Startups de Florianópolis.

O objetivo deste estudo visa indicar as possibilidades de atuação para profissionais da Biblioteconomia no Ecossistema de Startups de Florianópolis, e as competências, habilidades e atitudes fundamentais para esse ambiente, à luz das Competências para Profissionais da Informação da Special Libraries Association (SLA).

Para tanto, são apresentados tópicos relacionados aos procedimentos metodológicos empregados, a abordagem teórica necessária para a reflexão sobre os dados e, os resultados e discussão. 


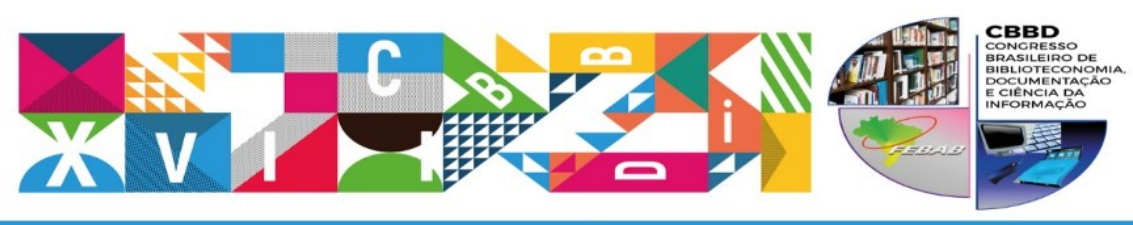

XXVII CONGRESSO BRASILEIRO DE BIBLIOTECONOMIA,

DOCUMENTAÇĀOO E CIÊNCIA DA INFORMAÇĀO

TEMA CENIRAL: Objetivos para o Desenvolvimento Sustentável das Naçōes Unidas:
como as bibliotecas podem contribuir com a implementaçāo da Agenda 2030

\section{PROCEDIMENTOS METODOLÓGICOS}

Este estudo pode ser classificado como exploratório-descritivo, pois realiza o mapeamento das competências, habilidades e atitudes indicadas para profissionais da Biblioteconomia inseridos no Ecossistema de Startups. 0 mapeamento ocorre a partir da caracterização de um Ecossistema de Startups, e à luz das Competências para Profissionais da Informação da SLA.

Com base na exploração e descrição realizadas, aplicou-se uma abordagem qualitativa para o entrecruzamento dos dados obtidos, com vistas a subsidiar uma discussão pertinente e relevante para o alcance do objetivo proposto.

\section{ECOSSISTEMA, STARTUPS E FLORIANÓPOLIS}

Startup é um termo utilizado para empresas novas, até mesmo embrionárias ou ainda em fase de constituição, que contam com projetos promissores, ligados à pesquisa, investigação e desenvolvimento de ideias inovadoras com baixos custos iniciais, sendo altamente escaláveis, ou seja, possuindo expectativa de crescimento quando dão certo.

Steve Blank, pesquisador responsável por um dos conceitos de startup, aborda startup como empresa em busca um modelo de negócios viável, repetível e escalável (BLANK, 2007). Por viável, entende-se um modelo de negócios possível de aplicar, por repetível que pode ser reproduzido, e por escalável que tem prospecção de crescimento incrementando nos produtos e serviços gerados ou gerando outros novos.

Embora muito próximo do conceito de pequenas empresas, as startups apresentam estrutura diferenciada, principalmente no que tange a sua base se fixar essencialmente em inovações tecnológicas. Nesse sentido, essas empresas acabam por penetrar em quase todas as áreas da sociedade. (STARTUP GENOME, 2017). 


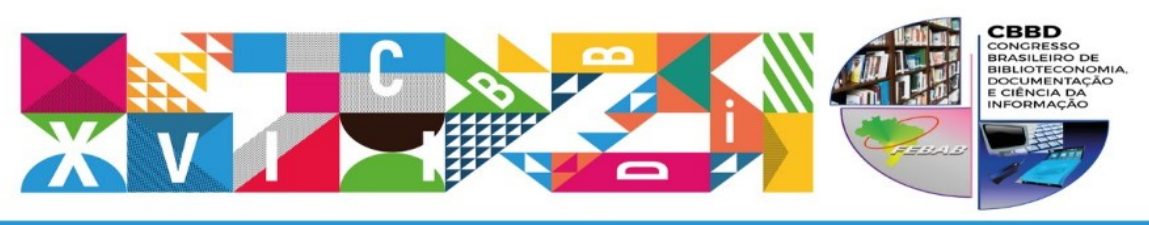

XXVII CONGRESSO BRASILEIRO DE BIBLIOTECONOMIA,

DOCUMENTAÇĀO E CIÊNCIA DA INFORMAÇĀO

TEMA CENIRAL: Objetivos para o Desenvolvimento Sustentável das Naçōes Unidas:
como as bibliotecas podem contribuir com a implementaçăo da Agenda 2030

No Brasil a popularização das startups, embora recente tem se destacado como fonte de inspiração para diversas iniciativas de criação e desenvolvimento desse tipo de empresa em várias cidades. Fato verificável pela existência, por exemplo, de uma associação específica, a Associação Brasileira de Startups (ABStartups), fundada em 2011 com o objetivo de "promover e representar as startups brasileiras", e com a missão de "[...] tornar o Brasil uma das cinco maiores potências em inovação e empreendedorismo tecnológico" (ABSTARTUPS, 2017).

Somada a criação da ABStartups em 2011, em 2016 o Congresso Nacional aprovou o novo marco legal da inovação por meio do decreto e sanção da Lei no 13.243 , de 11 de janeiro de 2016, que dispõe sobre estímulos ao desenvolvimento científico, à pesquisa, à capacitação científica e tecnológica e à inovação. Conhecida como Código da Ciência, Tecnologia e Inovação (C.T\&I), a lei é resultante de cinco anos de discussões entre os atores do Sistema Nacional de Inovação (SNI), nas esferas das Comissões de Ciência e Tecnologia da Câmara e do Senado (RAUEN, 2016).

O decreto e sanção da Lei no 13.243 permite que os estados e municípios brasileiros impulsionem suas ações de promoção da inovação, como no caso de Santa Catarina, por exemplo, em que já existia o Decreto nº 2.372, de 9 de junho de 2009, que regulamenta a Lei no 14.328, de 15 de janeiro de 2008, que dispõe sobre incentivos à pesquisa científica e tecnológica e à inovação no ambiente produtivo no Estado de Santa Catarina e estabelece outras providências.

Tais incentivos legais federais e estaduais podem direta e indiretamente influenciar no fato de Florianópolis em Santa Catariana ocupar posições de destaque no cenário nacional, e até mundial. Conforme verifica-se em Espíndola (2016) e Rodrigues (2017).

Nessa perspectiva, a Secretaria da Casa Civil Municipal de Florianópolis divulgou o Decreto no 17.097, de 27 de janeiro de 2017, que regulamenta a lei complementar nำ432, de 2012, que dispõe sobre sistemas, mecanismos e incentivos à atividade tecnológica e 


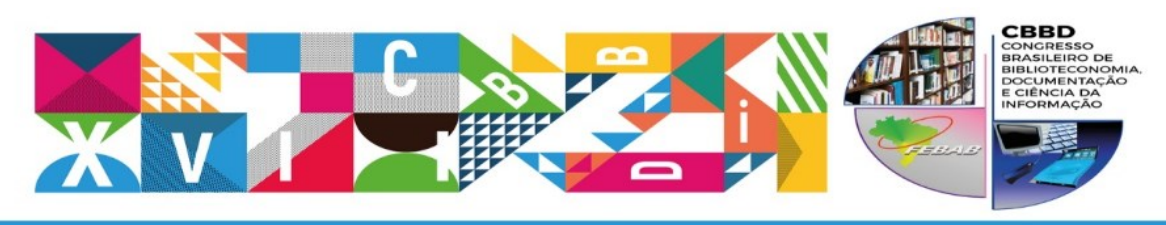

XXVII CONGRESSO BRASILEIRO DE BIBLIOTECONOMIA,

DOCUMENTAÇĀO E CIÊNCIA DA INFORMAÇĀO

TeMA CeENRRAL: Objetivos para o Desenvolvimento Sustentável das Naçōes Unidas:
como as bibliotecas podem contribuir com a implementaçáo da Agenda 2030

inovativa, visando o desenvolvimento sustentável do munícipio de Florianópolis e estabelece outras providências.

Em 10 de julho de 2017, a cidade aderiu oficialmente uma iniciativa do Serviço Brasileiro de Apoio às Micro Pequenas Empresas (SEBRAE) em parceria com as prefeituras municipais do Estado de Santa Catarina, o programa Cidade Empreendedora (ECONOMIASC, 2017).

Todo esse contexto de ações emergentes da legislação, associação, instituições, empreendedores e investidores favorecem de alguma forma o fomento dos ecossistemas favoráveis às startups.Estruturas que assim podem ser nomeadas, por se constituírem nasperspectivas de Moore (2006) e Lemos (2012), de organizações, indivíduos e outros grupos de interesse, que realizam atividades de negócios e econômicos.

Desse modo, o conceito de ecossistema, originário da biologia, embora com integrantes diferentes permanece com seu sentido de reunião de organismos bióticos ou abióticos que se relacionam em um processo de mútua interação, nos limites do ambiente que integram (LEMOS, 2012; MOORE, 2006). Adequando ao Ecossistema de Startups, é possível defini-lo como um ambiente favorável a interação mútua entre distintos atores, com vistas ao desenvolvimento de startups.

Feld (2012) corrobora com o conceito ao abordar que, essas comunidades consistem de muitos outros atores, além de empresários. Governo, universidades, investidores, mentores, prestadores de serviços e grandes empresas desempenham papéis fundamentais no desenvolvimento de Ecossistema de Startups.

Nesse sentido, cada ator integrante do Ecossistema de Startups possuí relevante papel no desenvolvimento de ações que aumentem o desempenho desse ambiente (TEIXEIRA; TRZECIAK; VARVAKIS, 2017). Por exemplo: universidades, importantes por serem formadores de talentos, primordiais para a constituição de equipes qualificadas dentro das startups; investidores, por disponibilizarem capital; governo, por criar um ambiente regulatório adequado, com legislação e incentivos que proporcionam o Revista Brasileira de Biblioteconomia e Documentação - v. 13, n. esp. CBBD 2017 


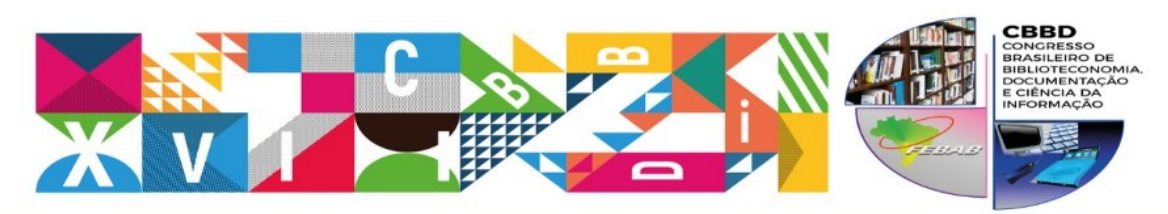

XXVII CONGRESSO BRASILEIRO DE BIBLIOTECONOMIA,

DOCUMENTAÇÃOO E CIÊNCIA DA INFORMAÇÃO

TEMA CENIRAL: Objetivos para o Desenvolvimento Sustentável das Naçōes Unidas:
como as bibliotecas podem contribuir com a implementaçăo da Agenda 2030

desenvolvimento das startups e sua interação com os demais atores do ecossistema (FONTE, 2016).

Florianópolis em Santa Catarina pode ser considerada uma cidade que fomenta a estrutura de um Ecossistema de Startups. O Sapiens Parque, para exemplificar, é a materialização de uma parceria entre Governo do Estado de Santa Catarina e a Fundação de Centros de Referência em Tecnologia Inovadoras (CERTI), para o desenvolvimento econômico, social, tecnológico e ambiental de Florianópolis. Uma vez que, baseia-se no conceito de Parque de Inovação, no sentido de propor a criação de uma infraestrutura necessária para proporcional a convergência de conhecimentos, ideias e projetos (SAPIENS PARQUE, 2017).

Posto isso, torna-se pertinente indicar as possibilidades de atuação para profissionais da Biblioteconomia no Ecossistema de Startups de Florianópolis, e as competências, habilidades e atitudes importantes para esse ambiente.

\section{BIBLIOTECONOMIA EM FLORIANÓPOLIS E A SLA}

Em Florianópolis existem dois cursos de graduação em Biblioteconomia, um na Universidade Federal de Santa Catarina (UFSC), outro na Universidade do Estado de Santa Catarina (UDESC). Com mais de 40 anos de existência, esses cursos apresentam credibilidade e são referências, tanto em relação a seus docentes, pesquisadores atuantes nas áreas de Ciência da Informação e especificamente na Biblioteconomia, bem como em relação a seus egressos, profissionais presentes em organizações públicas e privadas no estado de Santa Catarina e no Brasil.

Além disso, é perceptível pelos objetivos de ambos os cursos (UDESC, 2007; UFSC, 2015) a preocupação com o carácter interdisciplinar de atuação, a fim de garantir a seus egressos mais possibilidades de inserção no mercado de trabalho e na sociedade como um todo. 


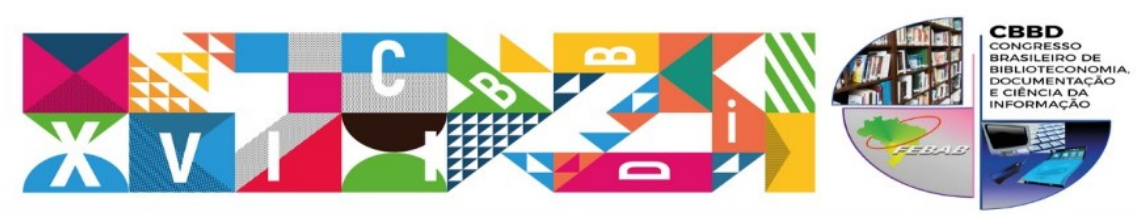

XXVII CONGRESSO BRASILEIRO DE BIBLIOTECONOMIA,

DOCUMENTAÇĀOO E CIÊNCIA DA INFORMAÇÃOO

TEMA CENIRAL: Objetivos para o Desenvolvimento Sustentável das Naçōes Unidas:
como as bibliotecas podem contribuir com a implementaçăo da Agenda 2030

O objetivo do Curso de Biblioteconomia - Habilitação Gestão da Informação UDESC é o de "Formar bibliotecários aptos para produzir e utilizar conhecimentos técnicocientíficos na gestão da informação para suprir às necessidades informacionais da sociedade." (UDESC, 2007).

O Curso de Graduação em Biblioteconomia UFSC tem por objetivo:

Formar bibliotecários com uma visão crítica da sociedade, imbuídos do compromisso com a gestão e a disseminação da informação, com consciência do seu papel científico e social na facilitação do acesso à informação seja de natureza política, tecnológica, econômica, educacional, social, cultural ou recreativa. (UFSC, 2015)

Verifica-se que esse contexto educacional vai ao encontrodas Competências para Profissionais de Informação indicadas pela SLA, uma organização global sem fins lucrativos, voltada para profissionais da informação inovadores e seus parceiros estratégicos em negócios, governo, academias, entre outros (SLA, 2016).

Essa organização tem por missão promover e fortalecer seus membros por meio de iniciativas de aprendizados, advocacia e redes. Seus valores fundamentais envolvem:

Liderança -Fortalecendo nossos papéis como líderes de informação em nossas organizações e em nossas comunidades, incluindo a formulação de políticas de informação.

Serviço -Respondendo às necessidades de nossos clientes, agregando valor qualitativo e quantitativo aos serviços e produtos de informação.

Inovação e Aprendizagem Contínua- Abraçando soluções inovadoras para o aprimoramento de serviços e o avanço intelectual na profissão.

Resultados e Responsabilidade - Fornecendo resultados mensuráveis na economia da informação e em nossas organizações. Espera-se que a Associação e seus membros operem com o mais alto nível de ética e honestidade.

Colaboração e Parcerias - Fornecendo oportunidades para se reunir, comunicar, colaborar e se associar no setor de informação e na comunidade empresarial.

Política Antiassédio- Empenhando-se em proporcionar um espaço seguro e igual para participação profissional para todos os nossos membros, Revista Brasileira de Biblioteconomia e Documentação - v. 13, n. esp. CBBD 2017 


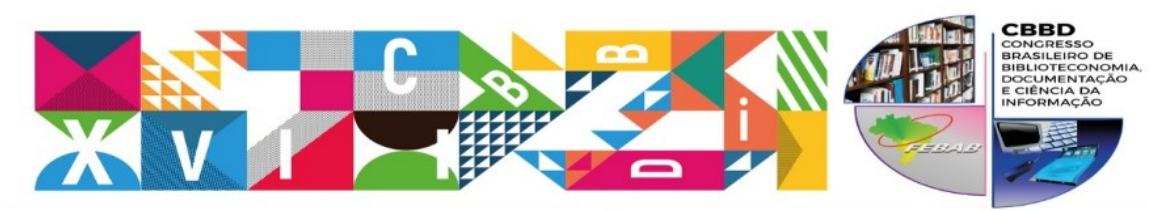

XXVII CONGRESSO BRASILEIRO DE BIBLIOTECONOMIA, DOCUMENTAÇÃOO E CIÊNCIA DA INFORMAÇĀO

TEMA CENIRAL: Objetivos para o Desenvolvimento Sustentável das Naçōes Unidas:
como as bibliotecas podem contribuir com a implementação da Agenda 2030

parceiros e participantes do evento. Acreditamos que todos têm direito à interação profissional sem medo, intimidação ou inadimplência e que todos têm direito a uma participação e tratamento justos e iguais. (SLA, 2016, tradução e grifos nossos)

Dessa forma, na indicação de Competências para Profissionais de Informação, a SLA aborda que os dados, informação e conhecimento são essenciais para as organizações modernas da sociedade contemporânea. E ainda destaca a importância do gerenciamento efetivo e o uso de informações para o crescimento e prosperidade dos indivíduos e das organizações (SLA, 2016).

Por conseguinte, como resultados do que foi abordado até aqui, realiza-se na próxima seção o entrecruzamento da lista de Competências para Profissionais de Informação da SLA com as características de um Ecossistema de Startups, a fim de cumprir o objetivo estabelecido para este artigo.

\section{RESULTADOS E DISCUSSÃO}

A SLA (2016), por meio do documento sobre as Competências para Profissionais da Informação apresenta seis competências básicas, com suas características e elementos, conforme Quadro 1.

Essa relação de competências é produto de uma força tarefa intitulada "SLA CompetenciesTask Force", que começou seu trabalho em junho de 2015. Esta iniciou a coleta de dados com aproximadamente 50 membros, no café do conhecimento na Conferência Anual SLA 2015, e a posteriori conseguiu a participação de 270 profissionais. Os dados foram analisados quantitativamente e os comentários foram marcados usando o software de análise de texto atlas.ti. Ademais, a força-tarefa revisou uma grande diversidade de documentação existente relacionada às competências dos profissionais de informação e bibliotecários, incluindo o trabalho anterior do SLA (versões de 1997, 2003 e 

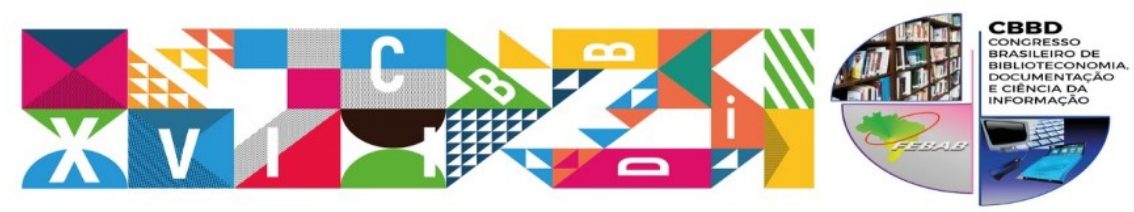

XXVII CONGRESSO BRASILEIRO DE BIBLIOTECONOMIA,

DOCUMENTAÇĀOO E CIÊNCIA DA INFORMAÇĀO

TEMA CENIRAL: Objetivos para o Desenvolvimento Sustentável das Naçōes Unidas:
como as bibliotecas podem contribuir com a implementação da Agenda 2030

2014), bem como as declarações de competências de outras associações e organizações de bibliotecários e profissionais da informação (SLA, 2016).

Quadro 1-Competências básicas, características e elementos para Profissionais da Informação

\begin{tabular}{|c|c|c|}
\hline Competências & Características & Elementos \\
\hline $\begin{array}{lr}1 \text { Serviços } & \text { de } \\
\text { Informação } & \mathrm{e} \\
\text { Conhecimento } & \end{array}$ & $\begin{array}{l}\text { Atender às necessidades de } \\
\text { informação e conhecimento das } \\
\text { organizações e comunidades, } \\
\text { fornecendo uma diversidade de } \\
\text { serviços baseados em uma } \\
\text { compreensão do comportamento } \\
\text { da informação humana e uma } \\
\text { avaliação holística da comunidade } \\
\text { ou organização. }\end{array}$ & $\begin{array}{l}1 \text { Reconhecer e articular das necessidades de } \\
\text { informação e conhecimento; } \\
2 \text { Analisar fluxos de informação e } \\
\text { conhecimento relevantes para o contexto de } \\
\text { características da comunidade e objetivos } \\
\text { organizacionais; } \\
3 \text { Permitir e compartilhar conhecimentos } \\
\text { através de contatos e relações interpessoais, } \\
\text { bem como através de sistemas e processos } \\
\text { digitais ou electrónicos; } \\
4 \text { Priorizar serviços de informação para } \\
\text { atender às necessidades operacionais ou } \\
\text { estratégicas mais críticas da organização; } \\
5 \text { Advogar para o uso efetivo e gerenciamento } \\
\text { de sistemas e processos de informação; } \\
6 \text { Ensinar, capacitar e desenvolvera } \\
\text { alfabetização em informações e habilidades } \\
\text { associadas para as partes interessadas; } \\
7 \text { Usar habilidades de gerenciamento de } \\
\text { informações para aprender sobre um } \\
\text { domínio, disciplina ou indústria; } \\
\mathbf{8} \text { Aplicar conhecimentos de domínio de } \\
\text { assunto ao ambiente de trabalho para apoiar } \\
\text { a missão organizacional; e, } \\
9 \text { Compreender os diversos aspectos do } \\
\text { comportamento da informação humana. }\end{array}$ \\
\hline $\begin{array}{l}2 \text { Sistemas } \\
\text { Tecnologia de } \\
\text { Informação } \\
\text { Conhecimento }\end{array}$ & $\begin{array}{lll}\text { Utilizar as } & \text { tecnologias } & \text { de } \\
\text { informação e comunicação de } & \text { de } \\
\text { forma eficaz para atender às } \\
\text { necessidades de informação e } \\
\text { conhecimento de suas } \\
\text { comunidades e organizações. }\end{array}$ & $\begin{array}{l}1 \text { Envolver múltiplos atores para recomendar } \\
\text { a arquitetura de informação necessária para } \\
\text { toda a organização; } \\
2 \text { Selecionar e implementar sistemas de } \\
\text { informação e conhecimento; } \\
3 \text { Selecionar e utilizar ferramentas de } \\
\text { gerenciamento de informações; } \\
4 \text { Identificar sistemas e ferramentas para } \\
\text { atender aos requisitos de comunidades } \\
\text { específicas; } \\
5 \text { Projetar interfaces para uma experiência de } \\
\text { usuário intuitiva; } \\
6 \text { Codificar usando scripts apropriados e } \\
\text { outras ferramentas; }\end{array}$ \\
\hline
\end{tabular}



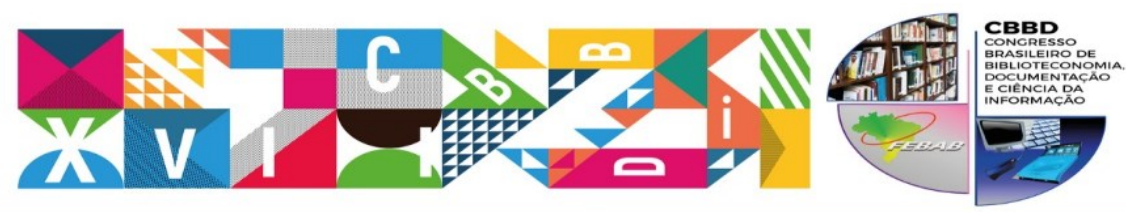

\section{CONGRESSO BRASILEIRO DE BIBLIOTECONOMIA, DOCUMENTAÇÃOO E CIÊNCIA DA INFORMAÇĀO \\ TEMA CENIRAL: Objetivos para o Desenvolvimento Sustentável das Naçōes Unidas:
como as bibliotecas podem contribuir com a implementação da Agenda 2030}

\begin{tabular}{|c|c|c|}
\hline & & 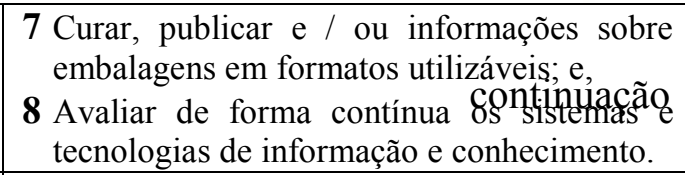 \\
\hline $\begin{array}{lr}\text { Recursos } & \text { de } \\
\text { Informação } & \mathrm{e} \\
\text { Conhecimento } & \end{array}$ & $\begin{array}{l}\text { Manter um } \\
\text { conhecimento dos recursos de } \\
\text { conteúdo disponíveis para atender } \\
\text { às necessidades das comunidades } \\
\text { que servem, com conhecimento } \\
\text { de todos os tipos de fontes e } \\
\text { mídia. } \\
\text { sistematicamente recursos de } \\
\text { potencial valor e priorizando a } \\
\text { aquisição de recursos com base no } \\
\text { julgamento do valor de cada } \\
\text { recurso para a comunidade. } \\
\text { Monitorando o mercado de } \\
\text { informações e negociando } \\
\text { efetivamente com fornecedores de } \\
\text { informações e fornecedores de } \\
\text { conteúdo. }\end{array}$ & 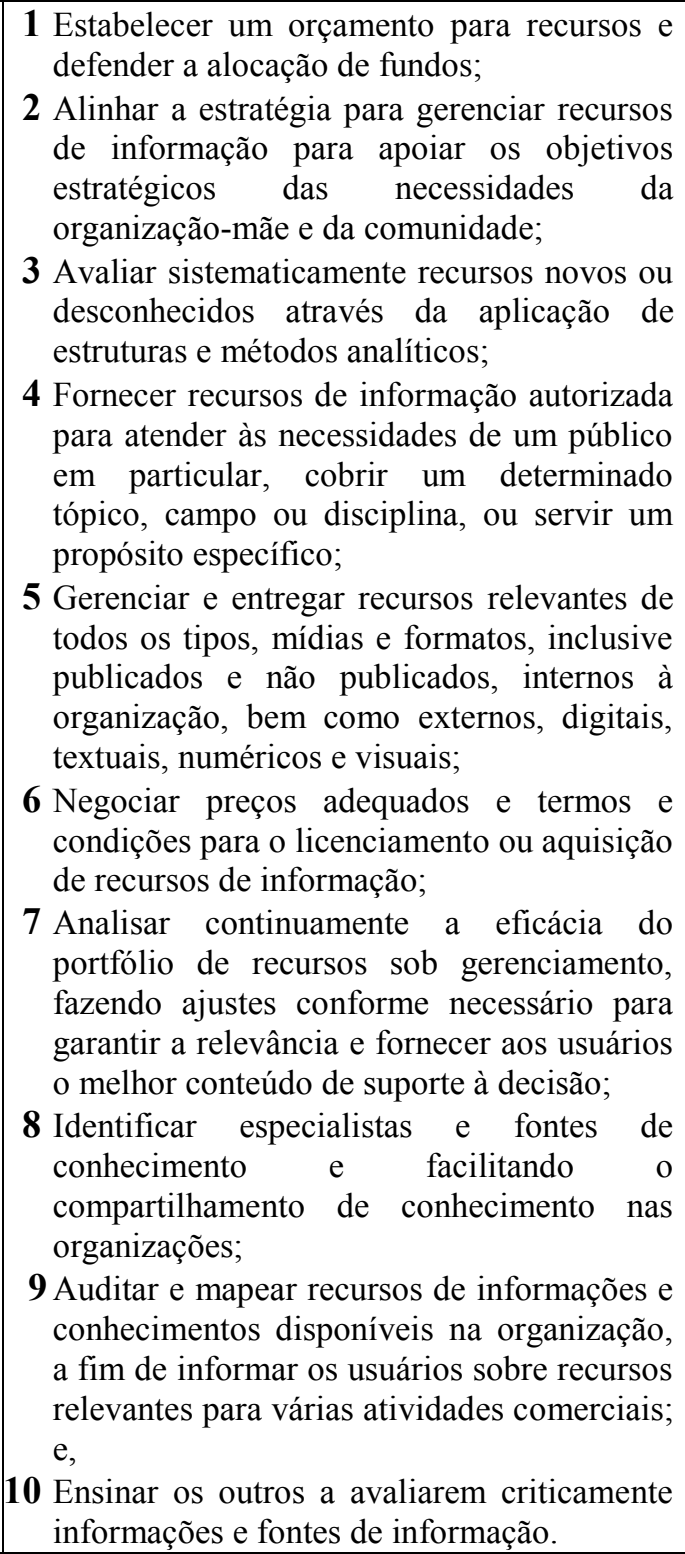 \\
\hline $\begin{array}{l}4 \text { Recuperação e } \\
\text { Análise de Dados } \\
\text { e Dados }\end{array}$ & $\begin{array}{l}\begin{array}{l}\text { Descobrir e obter } \\
\text { efetivamente, }\end{array} \\
\text { informações } \\
\text { necessário, por indivíduos e } \\
\text { grupos dentro de } \\
\text { comunidades, a partir de um } \\
\text { profundo conhecimento das }\end{array}$ & $\begin{array}{l}1 \text { Entrevistar e consultar os membros da } \\
\text { comunidade para identificar e esclarecer as } \\
\text { necessidades de informação } \\
\text { conhecimento; } \\
2 \text { Desenvolver sofisticadas estratégias de }\end{array}$ \\
\hline
\end{tabular}




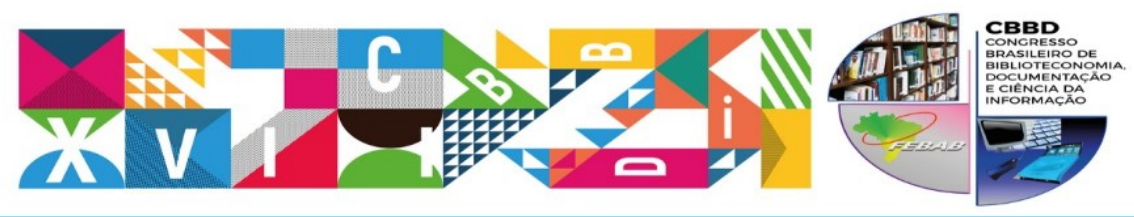

XXVII CONGRESSO BRASILEIRO DE BIBLIOTECONOMIA,

DOCUMENTAÇÃOO E CIÊNCIA DA INFORMAÇĀO

TEMA CENIRAL: Objetivos para o Desenvolvimento Sustentável das Naçōes Unidas:
como as bibliotecas podem contribuir com a implementaçăo da Agenda 2030

\begin{tabular}{|c|c|c|}
\hline & $\begin{array}{l}\text { funções do mecanismo de busca e } \\
\text { recuperação que permitem } \\
\text { realizar tarefas de recuperação de } \\
\text { informações complexas e difíceis. } \\
\text { Aplicando ferramentas e métodos } \\
\text { de análise de informações para } \\
\text { extrair significado e insights } \\
\text { acionáveis das informações } \\
\text { recuperadas. }\end{array}$ & $\begin{array}{l}\text { busca e recuperação para descobrir e } \\
\text { recuperar informações de sistemas e } \\
\text { repositórios variados; } \\
3 \text { Compreender os mecanismos de busca e os } \\
\text { sistemas de recuperação de informações, } \\
\text { incluindo as funcionalidades únicas } \\
\text { fornecidas por diferentes sistemas, e aplicar } \\
\text { esse entendimento aos projetos de pesquisa } \\
\text { e recuperação de informações; } \\
4 \text { Avaliar a veracidade ou qualidade das } \\
\text { informações e suas fontes subjagennternưuas } \\
\text { mecanismos de busca e pesquisa de } \\
\text { informações; } \\
5 \text { Utilizar a análise de dados apropriada, } \\
\text { análise de texto, visualização e ferramentas } \\
\text { similares para analisar informações para } \\
\text { extrair informações e significado; } \\
6 \text { Comunicar os resultados dos projetos de } \\
\text { recuperação e análise de informações de } \\
\text { forma que seja utilizável e acionável pelo } \\
\text { público-alvo; e, } \\
7 \text { Ensinar todas as competências em uma } \\
\text { variedade de configurações formais e } \\
\text { informais. }\end{array}$ \\
\hline $\begin{array}{lr}5 \text { Organização } & \text { de } \\
\text { Dados, } & \\
\text { Informação } & \text { e } \\
\text { Recursos } & \text { de } \\
\text { Conhecimento } & \end{array}$ & $\begin{array}{l}\text { Organizar e gerenciar recursos de } \\
\text { dados, informações e } \\
\text { conhecimento, de modo que } \\
\text { sejam consideráveis, utilizáveis e } \\
\text { acessíveis ao longo da vida } \\
\text { definida. Estabelecer políticas } \\
\text { para a organização, preservação e } \\
\text { retenção desses ativos, levando } \\
\text { em consideração a missão e as } \\
\text { necessidades operacionais de sua } \\
\text { instituição. Estabelecer requisitos } \\
\text { e procedimentos para metadados e } \\
\text { avaliam e adaptam os padrões da } \\
\text { indústria para sistemas de } \\
\text { classificação e categorização, } \\
\text { armazenamento e preservação, } \\
\text { localização e conectividade para } \\
\text { garantir que os ativos sejam } \\
\text { devidamente gerenciados. }\end{array}$ & $\begin{array}{l}1 \text { Aplicar práticas profissionais padrão para } \\
\text { metadados descritivos e sujeitos a ativos de } \\
\text { informações; } \\
2 \text { Desenvolver esquemas de metadados } \\
\text { personalizados; } \\
3 \text { Desenvolver taxonomias e ontologias } \\
\text { personalizadas, conforme as circunstâncias } \\
\text { locais o justifiquem; } \\
4 \text { Desenvolver políticas e procedimentos de } \\
\text { retenção e destruição com base em } \\
\text { requisitos legais e necessidades operacionais } \\
\text { organizacionais; } \\
5 \text { Treinar outros em práticas efetivas para } \\
\text { organização e gerenciamento de } \\
\text { informações; práticas de controle de qualidade } \\
6 \text { Aplicar prática } \\
\text { para assegurar a aplicação apropriada de } \\
\text { políticas e práticas para organização e } \\
\text { gerenciamento de informações; e, } \\
7 \text { Coordenar o desenvolvimento e a } \\
\text { implementação de sistemas e processos } \\
\text { arquivísticos personalizados para suportar as } \\
\text { necessidades organizacionais. }\end{array}$ \\
\hline 6 Ética & Combinar um forte fundamento & 1 Reconhecer questões éticas relativas à \\
\hline
\end{tabular}




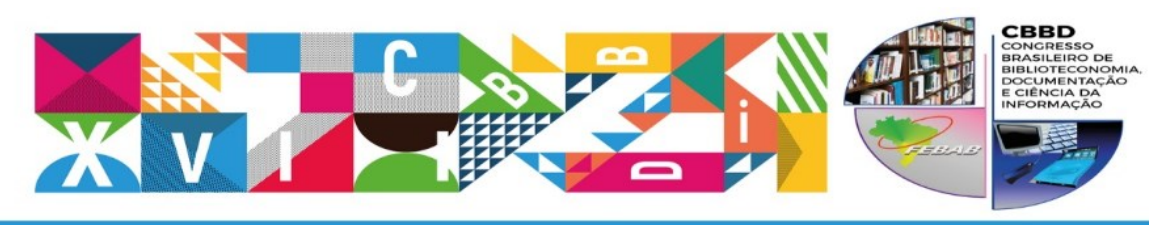

XXVII CONGRESSO BRASILEIRO DE BIBLIOTECONOMIA,

DOCUMENTAÇĀO E CIÊNCIA DA INFORMAÇĀO

TEMA CENIRAL: Objetivos para o Desenvolvimento Sustentável das Naçōes Unidas:
como as bibliotecas podem contribuir com a implementaçāo da Agenda 2030

\begin{tabular}{|c|c|c|}
\hline Informação & $\begin{array}{l}\text { moral e ético com um alerta para } \\
\text { questões que comumente } \\
\text { emergem no trabalho relacionado } \\
\text { à informação e ao conhecimento. } \\
\text { Conhecer e aderir aos padrões de } \\
\text { conduta profissionais formulados } \\
\text { pela Associação de Bibliotecas } \\
\text { Especiais e outras organizações } \\
\text { profissionais aplicáveis. Conhecer } \\
\text { e aderir ao código de ética de seu } \\
\text { empregador. }\end{array}$ & $\begin{array}{l}\text { manipulação de informações, incluindo, } \\
\text { entre outras, a privacidade e } \\
\text { confidencialidade, segurança da informação, } \\
\text { propriedade intelectual e direitos autorais e } \\
\text { liberdade intelectual; } \\
\mathbf{2} \text { Modelar comportamento de informação } \\
\text { ética; } \\
\mathbf{3} \text { Ensinar, influenciar e treinar outros; } \\
\mathbf{4} \text { Contribuir para políticas organizacionais, } \\
\text { procedimentos e outras iniciativas; e, } \\
\mathbf{5} \text { Avaliar e auditando a implementação } \\
\text { organizacional da ética da informação. }\end{array}$ \\
\hline
\end{tabular}

Fonte:Elaborado pelas Autoras, baseado nas informações da SLA (2016).

No documento aborda-se ainda uma lista de habilidades pertinentes para a concretização dessas competências, a saber:

1 Pensamento crítico, incluindo o raciocínio qualitativo e quantitativo;

2 Iniciativa, adaptabilidade, flexibilidade, criatividade, inovação e resolução de problemas;

3 Comunicação oral e escrita eficaz, incluindo habilidades de influência;

4 Construção de relacionamentos, redes e colaboração, incluindo a capacidade de promover o respeito, a inclusão e a comunicação entre indivíduos diversos;

5 Marketing;

6 Liderança, gerenciamento e gerenciamento de projetos;

7 Aprendizagem ao longo da vida;

8 Desenho e desenvolvimento instrucional, ensino e orientação; e

9 Ética de negócios.

As características, elementos e habilidades inerentes às competências elencadas pela SLA (2016), levam a percepção da amplitude da atuação dos Profissionais da Informação, e especificamente do profissional da Biblioteconomia, uma vez que compõe esse grupo. 


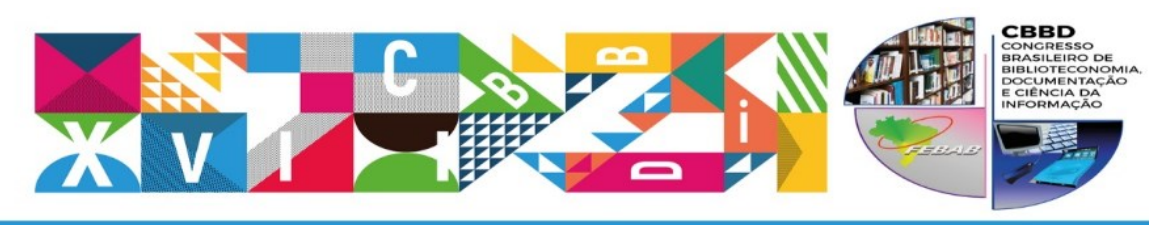

XXVII CONGRESSO BRASILEIRO DE BIBLIOTECONOMIA,

DOCUMENTAÇĀOO E CIÊNCIA DA INFORMAÇĀO

TEMA CENTRAL: Objetivos para o Desenvolvimento Sustentável das Naçōes Unidas:
como as bibliotecas podem contribuir com a implementaçăo da Agenda 2030

É possível inferir que essas competências são pertinentes ao Ecossistema de Startups, conforme suas características e elementos. Já que, de acordo com Feld (2012) um Ecossistema de Startups possuí diversos atores interagentes em torno de um negócio. E segundo Teixeira; Trzeciak e Varvakis (2017), cada um desses atores possuí um papel primordial no desenvolvimento de ações que impulsionem o desempenho desse ambiente.

Deste modo, os conhecimentos advindos desses atores geram fluxos de informações que podem ser trabalhados de inúmeras maneiras por profissionais da área de Biblioteconomia, com vistas a potencializar o processo inovador presente em um Ecossistema de Startups, por meio de uma avaliação holística constante das necessidades informacionais existentes.

Identifica-se assim mais especificamente, possibilidades de atuação referentes a gestão da documentação, gestão da informação, análise de informação, gestão do conhecimento, curadoria, consultoria no que concerne a elaboração de projetos, mapeamento de fontes de informação pertinentes, disseminação seletiva da informação, entre outras e, destaca-se por último a inserção como empreendedor de novas tecnologias.

\section{CONSIDERAÇÕES FINAIS}

O estudo torna perceptível e necessária a participação do profissional da Biblioteconomia no contexto do Ecossistema de Startups de Florianópolis. Ao cruzar as Competências para Profissionais da Informação da Special Library Associationcom as características de um Ecossistema de Startups, verificou-se que estas são pertinentes, em virtude dessas comunidades se constituírem baseadas na multiplicidade de conhecimentos de distintos atores no fluxo da informação.

Portanto, ao compreender a indicação de possibilidades de atuação para os profissionais da Biblioteconomia no Ecossistema de Startups, possibilita-se mostrar o que e 


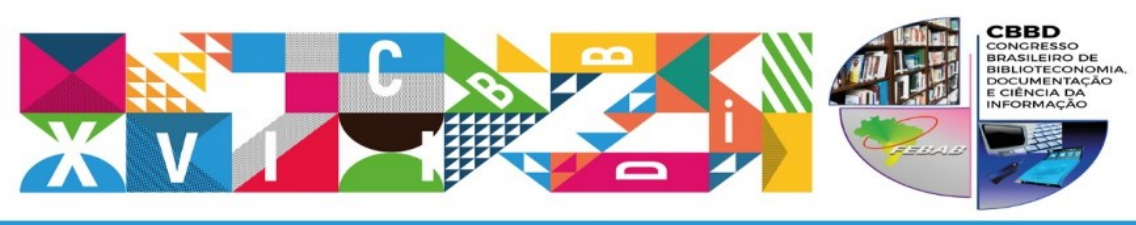

XXVII CONGRESSO BRASILEIRO DE BIBLIOTECONOMIA,

DOCUMENTAÇĀO E CIÊNCIA DA INFORMAÇĀO

TEMA CENIRAL: Objetivos para o Desenvolvimento Sustentável das Naçōes Unidas:
como as bibliotecas podem contribuir com a implementaçăo da Agenda 2030

como interagir nesse ambiente, no qual o mais importante é saber organizar e acessar a informação conforme a necessidade do público.

Ao observar tendências internacionais e nacionais sobre os impactos dos parques tecnológicos no crescimento da inovação,identifica-se o estudo de Lamperti, Mavilia e Castellini (2017).

Sobre a educação de competências, habilidades e atitudes necessárias, com vistas a fortalecer a base teórica e práticas na área de inovação e startups,Bischoff, Volkmann eAudretsch (2017, p. 14) revelam a colaboração ativa com incubadoras e / ou aceleradores no fornecimento de educação para empreendedorismo. As formas de colaboração são desde palestrantes convidados por representantes de incubadoras ou aceleradores, intercâmbio extensivo de conhecimentos e ligação em rede entre acadêmicos e profissionais, organização conjunta de seminários, projetos, workshops, conferências e outros eventos. De longe, a forma mais comum de envolvimento das partes interessadas está o incentivo e apoio de criação inovadora por meio da provisão de financiamento, coaching, consultoria empresarial, expertise e infraestrutura ou espaço de escritório.

Wright, Siegel, Mustar (2017) apresentam um diagrama sobre o ecossistema do ambiente universitário, no intuito de favorecer o desenvolvimento de startups pelos estudantes. Quanto ao ciclo de vida de cada elemento dos ecossistemas, há a necessidadede mais estudos, e principalmente no que concerne ao contexto envolvendo universidades, empresas e pessoas que fortaleçam as estruturas mais adequadas.

Diante do exposto, verifica-se que a inovação nos diferentes ambientes da informação apresenta distintas nuances. A criatividade existe no cotidiano do ser perante o que fazer e como aproveitar os momentos para a melhoria contínua em produtos, serviços, tarefas e atividades. Destaforma, o fundamental é manter uma atitude aberta ao novo, preparando-se para mudanças constantes e rápidas nessa aldeia global.

\section{REFERÊNCIAS}

Revista Brasileira de Biblioteconomia e Documentação - v. 13, n. esp. CBBD 2017 


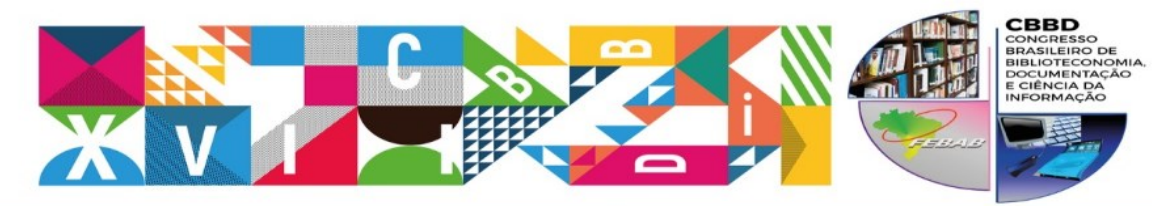

XXVII CONGRESSO BRASILEIRO DE BIBLIOTECONOMIA,

DOCUMENTAÇÃO E CIÊNCIA DA INFORMAÇĀO

TEMA CENTRA: : Objetivos para o Desenvolvimento Sustentável das Naçōes Unidas:
como as bibliotecas podem contribuir com a implementação da Agenda 2030

ABSTARTUPS. Sobre a ABStartups. Disponível: <https://abstartups.com.br/sobre-a-abstartups/> . Acessoem: 22 jun. 2017.

Bischoff, Kathrin; Volkmann, Christine K.; Audretsch, David B. Stakeholder collaboration in entrepreneurship education: an analysis of the entrepreneurial ecosystems of European higher educational institutions. The Journal of Technology Transfer , v. 42, n. 4, April, 1-27 Spring, 2017. Disponívelem: <https://link.springer.com/content/pdf/10.1007\%2Fs10961-017-9581-0.pdfe https://doi.org/10.1007/s10961-017-9581-0>Acessoem: 30 nov. 2017.

BLANK, Steve. Four steps to the epiphany. 2 ed.Cafepress, 2007.

BRASIL. Lei no 13.243, de 11 de janeiro de 2016. Dispõe sobre estímulos ao desenvolvimento científico, à pesquisa, à capacitação científica e tecnológica e à inovação e altera a Lei no 10.973, de 2 de dezembro de 2004, a Lei no 6.815, de 19 de agosto de 1980, a Lei no 8.666, de 21 de junho de 1993, a Lei no 12.462, de 4 de agosto de 2011, a Lei no 8.745, de 9 de dezembro de 1993, a Lei no 8.958, de 20 de dezembro de 1994, a Lei no 8.010, de 29 de março de 1990, a Lei no 8.032, de 12 de abril de 1990, e a Lei no 12.772, de 28 de dezembro de 2012, nos termos da Emenda Constitucional no 85, de 26 de fevereiro de 2015. Diário Oficial da União, Brasília, 2016. Disponível em: <http://goo.gl/gjDTBT>. Acesso em: 15 jul. 2017.

ECONOMIA SC. Florianópolis adere ao programa Cidade Empreendedora do Sebrae/SC. 2017. Disponível em: <http://economiasc.com.br/florianopolis-adere-ao-programa-cidadeempreendedora-do-sebraesc/>. Acesso em: 10 jul. 2017.

ENDEAVOR BRASIL. Índice de Cidades Empreendedoras (ICE). 2016. Disponível em: <http://info.endeavor.org.br/ice2016>. Acesso em: 10 jul. 2017.

ESPÍNDOLA, Marcos. Incubadoras e startups crescem e tornam Florianópolis referência. Especial do G1 SC, Florianópolis, 12 ago. 2016. Disponível em: <http://g1.globo.com/sc/santa-catarina/sc-queda-certo/noticia/2016/08/incubadoras-e-startups-crescem-e-tornam-florianopolis-referencia-nopais.html>. Acessoem: 10 jul. 2017.

FELD, B. Startup Communities: building na entrepreneurial ecosystem in your city. New Jersey: John Wiley\& Sons, Inc., 2012.

FLORIANÓPOLIS. Decreto 17.097, de 27 de janeiro de 2017. Regulamenta a lei complementar n. 432, de 2012, que dispõe sobre sistemas, mecanismos e incentivos à atividade tecnológica e inovativa, visando o desenvolvimento sustentável do município de Florianópolis e estabelece outras providências. Diário oficial eletrônico do munícipio de Florianópolis. Florianópolis, 30 jan. 2017. Disponível em:

<http://www.pmf.sc.gov.br/arquivos/diario/pdf/30_01_2017_19.18.50.7883c1281033732c1cc5ef 2b8db43371.pdf>. Acesso em: 19 mar. 2017. 


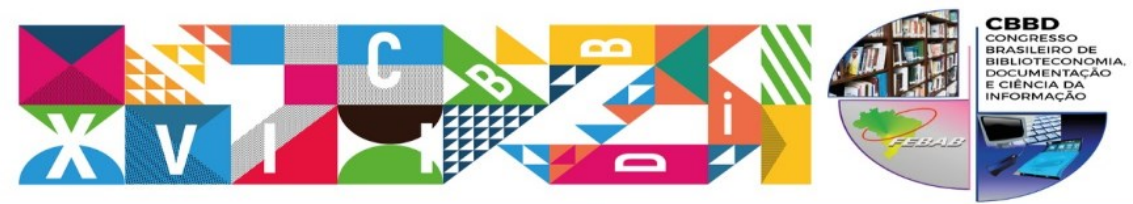

XXVII CONGRESSO BRASILEIRO DE BIBLIOTECONOMIA,

DOCUMENTAÇĀOO E CIÊNCIA DA INFORMAÇĀO

TEMA CENTRAL: Objetivos para o Desenvolvimento Sustentável das Naçóes Unidas:
como as bibliotecas podem contribuir com a implementaçăo da Agenda 2030

FONTE: tecnologia da informação na gestão pública. Belo Horizonte, Ano 13, n. 16, dez.2016/jan.2017. Disponível em: <https://www.prodemge.gov.br/revista-fonte/Publication/18As-startups-e-seus-ecossistemas\#page/1>. Acesso em: 10 jul. 2017.

LAMPERTI, Francesco, MAVILIA, Roberto; CASTELLINI, Simona. The Journal of Technology Transfer, v. 42, n. 158, Feb. , 2017 . Disponível em: <https://doi.org/10.1007/s10961-015-94552>. Acesso em: 30 nov. 2017.

LEMOS, Paulo Antonio Borges. Universidades e ecossistemas de empreendedorismo: a gestão orientada por ecossistemas e o empreendedorismo na UNICAMP. Campinas: Editora UNICAMP, 2012.

MOORE, James E. Business ecosystems and the view from the firm. The Antitrust Bulletin, v. 51, $\mathrm{n}$. 1, p. 31-75, Spring, 2006.Disponívelem: <https://www.ecosystemsinnovation.com/wpcontent/uploads/2017/09/Business-ecosystems-and-the-view-from-the-firm-antitrustbu_081320081450.pdf>.Acesso em: 10 jul. 2017.

RAUEN, Cristiane Vianna. O novo marco legal da inovação no Brasil: o que muda na relação ICTEmpresa. Radar, v. 43, p. 21-35, fev. 2016. Disponível em:

<https://www.almg.gov.br/export/sites/default/acompanhe/eventos/hotsites/2016/forum_tecnic o_startups/documentos/material_de_referencia/02artigo_novo_marco_legal_inovacao_cristiane_rau en.pdf>. Acesso em: 30 jan. 2017.

SANTA CATARINA. Decreto n. 2.372, de 9 de junho de 2009. Regulamenta a lei n. 14.328, de 15 de janeiro de 2008, que dispõe sobre incentivos à pesquisa científica e tecnológica e à inovação no ambiente produtivo no Estado de Santa Catarina e estabelece outras providências. Procuradoria Geral do Estado. Florianópolis, 2019. Disponível em:

<http://server03.pge.sc.gov.br/LegislacaoEstadual/2009/002372-005-0-2009-002.htm>. Acesso em: 19 mar. 2017.

SAPIENS Parque. Florianópolis, 2016. Disponível em:

<http://www.sapiensparque.com.br/pt/historia/>. Acesso em: 10 jul. 2017.

SPECIAL Libraries Association (SLA). About SLA. 2016. Disponível em:

<https://www.sla.org/about-sla/>. Acesso em: 10 jul. 2017.

SPECIAL Libraries Association (SLA). Competencies for InformationProfessionals. 2016. Disponível em: <https://www.sla.org/about-sla/competencies/>. Acessoem: 10 jul. 2017.

STARTUP GENOME. The Global Startup Ecosystem Report 2017. San Francisco : Startup Genome. 2017. Disponível em: <https://startupgenome.com/report2017/>. Acesso em: 15. jul. 2017. 


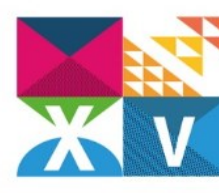

\section{CONGRESSO BRASILEIRO DE BIBLIOTECONOMIA, DOCUMENTAÇĀO E CIÊNCIA DA INFORMAÇĀO \\ TEMA CENIRal: Objetivos para o Desenvolvimento Sustentável das Naçōes Unidas:
como as bibliotecas podem contribuir com a implementaçăo da Agenda 2030}

TEIXEIRA, Clarissa S.; TRZECIAK, Dorzeli S.; VARVAKIS, Gregório. (Orgs.) Ecossistema de inovação: Alinhamento conceitual. Florianópolis: Perse, 2017. Disponível em: <http://via.ufsc.br/>. Acesso em: 15 jul. 2017.

UNIVERSIDADE DO ESTADO DE SANTA CATARINA (UDESC).Reformulação curricular e projeto pedagógico do Curso de Biblioteconomia - habilitação Gestão da Informação. 2007. Disponível em: <http://www.faed.udesc.br/arquivos/id_submenu/544/ppc_biblio_2007.pdf>. Acesso em: 15 jul. 2017.

UNIVERSIDADE FEDERAL DE SANTA CATARINA (UFSC). Projeto pedagógico do Curso de Graduação em Biblioteconomia da Universidade Federal de Santa Catarina. 2015. Disponível: <http://biblioteconomia.ufsc.br/files/2014/10/BBD_PPC_2016.pdf>. Acesso em: 15 jul. 2017.

WRIGHT, Mike; SIEGEL, Donald.S.; MUSTAR, Philippe. An emerging ecosystem for student startups.The Journal of Technology Transfer, v. 42, n. 4, p. 909 - 922, Aug. 2017.Disponível em:<https://doi.org/10.1007/s10961-017-9558-z>.Acesso em: 30 nov. 2017. 